\title{
Pharmacokinetics of acute tryptophan depletion using a gelatin-based protein in male and female Wistar rats
}

\author{
L. A. W. Jans · C. K. J. Lieben · L. T. Smits • \\ A. Blokland
}

Received: 22 February 2008/Accepted: 18 July 2008/Published online: 6 August 2008

(c) The Author(s) 2008. This article is published with open access at Springerlink.com

\begin{abstract}
The essential amino acid tryptophan is the precursor of the neurotransmitter serotonin. By depleting the body of tryptophan, brain tryptophan and serotonin levels are temporarily reduced. In this paper, several experiments are described in which dose and treatment effects of acute tryptophan depletion (ATD) using a gelatin-based protein-carbohydrate mixture were studied in male and female Wistar rats. Two or three doses of tryptophan depleting mixture resulted in $65-70 \%$ depletion after $2-4 \mathrm{~h}$ in males. ATD effects were similar in females, although females may return to baseline levels faster. Treatment effects after four consecutive days of ATD were similar to the effects of 1 day of treatment. Object recognition memory was impaired 2, 4, and $6 \mathrm{~h}$ after the first of two doses of ATD, suggesting that the central effects occurred rapidly and continued at least $6 \mathrm{~h}$, in spite of decreasing treatment effects on plasma tryptophan levels at that time point. The method of acute tryptophan depletion described here can be used to study the relationship between serotonin and behaviour in both male and female rats.
\end{abstract}

\footnotetext{
L. A. W. Jans · A. Blokland $(\bowtie)$

Department of Neuropsychology and Psychopharmacology, Faculty of Psychology, Maastricht University, PO Box 616, 6200 MD Maastricht, The Netherlands

e-mail: a.blokland@psychology.unimaas.nl

C. K. J. Lieben

Department of Surgery, Faculty of Medicine, Maastricht

University, PO Box 616, 6200 MD Maastricht, The Netherlands

L. T. Smits

Department of Psychiatry and Neuropsychology,

Faculty of Medicine, Maastricht University,

PO Box 616, 6200 MD Maastricht, The Netherlands
}

Keywords Serotonin $\cdot$ Tryptophan $\cdot$ Sex $\cdot$ Amino acids . Memory $\cdot$ Rat

\section{Introduction}

The neurotransmitter serotonin (5-hydroxytryptamine, 5-HT) plays a prominent role in various aspects of behaviour and is known to be involved in numerous psychiatric diseases (Maes and Meltzer 1995). Serotonin is synthesised from its amino acid precursor tryptophan (TRP), which is taken up from the blood. The level of TRP in plasma depends on the balance between the dietary intake of TRP and its removal from the plasma by protein synthesis and enzymatic degradation. Most of the TRP in plasma is protein-bound, with only 5\% available for transport into the CNS. Free TRP is transported into the brain across the blood-brain barrier by an active protein shuttle for which five other large neutral amino acids (LNAAs: valine, leucine, isoleucine, phenylalanine, tyrosine) also compete. The ratio of TRP and these other LNAAs (TRP/ $L$ LNAA ratio) is thought to be a more sensitive index of brain tryptophan availability (Fernstrom 1981; Wurtman et al. 1980), because it is this ratio that determines how much tryptophan can enter the brain. Once in the brain, TRP is converted into 5-HT by a two-step process catalysed by the enzymes tryptophan hydroxylase and aromatic amino acid decarboxylase.

Tryptophan hydroxylase is not fully saturated at normal brain TRP levels, hence the availability of TRP is the limiting factor in the synthesis of 5-HT. Because of this, factors that influence brain TRP levels can influence the rate of 5-HT synthesis. In the method of acute tryptophan depletion (ATD) brain 5-HT is lowered by depleting the body of TRP. Subjects ingest an amino 
acid load in the form of a drink. The mixture does not contain TRP, but does contain high levels of the other amino acids, resulting in a lowering of plasma TRP and the TRP/ $L$ LNAA ratio, thus restricting the entry of TRP into the brain. Due to its reversible and non-intrusive effects, the method of ATD can be used in animals and humans.

ATD lowers plasma TRP (Young et al. 1985) for several hours via increased competition for transport across the blood-brain barrier (Fernstrom 1981) and increased protein synthesis in the liver (Moja et al. 1991). Brain 5-HT levels are temporarily lowered (Biggio et al. 1974; Moja et al. 1989) and there is a decrease in brain 5-HT synthesis (Nishizawa et al. 1997) and concentrations of 5-HT (Bel and Artigas 1996) and its metabolite 5-hydroxyindolacetic acid (5-HIAA) (Carpenter et al. 1998; Stancampiano et al. 1997; Williams et al. 1999). The ATD method has been shown to affect various aspects of behaviour (Booij et al. 2003; Moore et al. 2000; Reilly et al. 1997). Impaired memory performance after ATD has been shown consistently in human (Park et al. 1994; Riedel et al. 1999) and animal studies (Lieben et al. 2004b).

Sex may affect several outcome measures of ATD. (Nishizawa et al. 1997) studied the effects of ATD on 5-HT synthesis and found that the rates of 5-HT synthesis were reduced by ATD by a factor of about 9.5 in men and a factor of about 40 in women. Apparently, the effect of ATD on 5-HT synthesis is larger in women than in men. Several previous ATD studies in which gender effects were considered showed that mood effects are larger in females than in males (Booij et al. 2002; Ellenbogen et al. 1996; Smith et al. 1997). In a mega-analysis, Sambeth et al. (2007) found that the effects of ATD on verbal memory were larger in women than in men on both the immediate and delayed recall scores, despite similar levels of depletion in males and females.

Previous studies in our lab have shown that ATD in male rats results in a temporary lowering of plasma TRP levels and TRP, 5-HT and 5-HIAA levels in several brain regions (Lieben et al. 2004a). In females, a temporary lowering of plasma TRP has been reported that was independent of the female estrous cycle phase, whereas depletion of brain TRP was stronger in females in proestrus and estrus compared to females in met-estrus and di-estrus (Jans et al. 2007a). Furthermore, reliable effects of ATD on memory $4 \mathrm{~h}$ after treatment have been found in male (Jans et al. 2007a; Lieben et al. 2004b) and female rats (Jans et al. 2007a). In this paper, we describe several experiments that were done to further characterise the pharmacokinetic effects of ATD, using a gelatin-based mixture, in male and female rats.

\section{Material and methods}

\section{Experiments}

A total of four experiments are described in this paper. In experiment 1, time and TRP-time and dose effects were studied in male rats. In experiment 2 , time and dose effects of acute TRP depletion and suppletion in females were studied in female rats. In experiment 3 , the effects of repeated ATD were studied in female rats. In experiment 4 the effects of ATD on object recognition in males are measured 2, 4 and $6 \mathrm{~h}$ after treatment.

Animals

In all experiments, subjects were 4-month-old Wistar rats, male or female (Charles River, The Netherlands). In experiment 2, 3, and 4 the rats were housed individually, while in experiment 1 they were housed per two. In all experiments, the rats were housed in standard Macrolon cages on sawdust bedding in an air-conditioned room $\left( \pm 21^{\circ} \mathrm{C}\right)$. The animals had free access to food and water. They were kept under a reversed 12/12-h light/dark cycle. The lights were on from 0600 to 1800 hours. A radio, which was playing softly, provided background noise. All experimental procedures were approved by the local ethical committee of the Maastricht University for animal experiments and met governmental guidelines.

\section{Materials}

The Gelatin hydrolysate (Solugel ${ }^{\circledR}$; Solugel $\mathrm{C}$ in experiment 1 and Solugel $P$ in experiments 2, 3, and 4) was obtained from PB Gelatins (Tessenderlo, Belgium). Glucodry 210 was obtained from the Amylumgroup (Koog aan de Zaan, The Netherlands). L-tryptophan was obtained from Sigma (Zwijndrecht, The Netherlands). Kaliumchloride $(\mathrm{KCl})$, calciumchloride-dihydrate $\left(\mathrm{CaCl}_{2} \cdot 2 \mathrm{H}_{2} \mathrm{O}\right)$ and 5-sulfosalicylic acid dihydrate were purchased from Merck (Darmstadt, Germany).

\section{Treatment}

During a period of 2 weeks preceding the experiment, the rats were handled and habituated to oral injections with normal tap water (up to $10 \mathrm{ml} / \mathrm{kg}$ ). On experimental days, the rats were fasted $14 \mathrm{~h}$ prior treatment until the testing period was completed. This was done to minimise the availability of TRP from food which would counteract the effects of the acute treatment. The rats were orally treated with a protein-carbohydrate mixture containing TRP (TRP + group, $0.28 \%$ TRP of the total protein) or one 
lacking TRP (TRP- group), or with saline (experiment 1). The composition of the nutritional mixture (with Solugel P) is shown in Table 1. In all experiments, one dose contained $4.0 \mathrm{~g}$ Solugel $\mathrm{C} / \mathrm{kg}$ and $2.0 \mathrm{~g}$ Glucodry $/ \mathrm{kg}$ of the body weight and was given in a volume of $10 \mathrm{ml} / \mathrm{kg}$ between 0830 and 1230 hours. Blood samples were taken at baseline (10 or $20 \mathrm{~min}$ before treatment) and at several time points after treatment. Specific treatment conditions and mean TRP values of each experiment are shown in Table 2 .

\section{Biochemistry}

For the determination of plasma amino acid levels blood samples were taken at resting values and repeated at several points in time. Blood sampling was done via a tail-incision method (Fluttert et al. 2000). Promptly after collection of blood in a sodium heparin tubes (Microvette ${ }^{\circledR}$ CB 300, Sarstedt, Germany), the samples were kept on ice. After centrifugation of the blood samples $\left(\right.$ at $4^{\circ} \mathrm{C}$ for $15 \mathrm{~min}$ at 3,000 $\mathrm{g}$ in a Hettich EBA 12 centrifuge), plasma was deproteinised with cups containing dry 5-sulfosalicylic acid $(6 \mathrm{mg} / 100 \mu \mathrm{l}$ plasma) and the protein was spun down. Samples were frozen in liquid nitrogen and stored at $-80^{\circ} \mathrm{C}$. Before analysis, samples were thawed at $4^{\circ} \mathrm{C}$,

Table 1 Composition of the protein-carbohydrate mixture

\begin{tabular}{lc}
\hline Protein $\left(\right.$ Solugel $\left.^{\circledR}\right)$ in $100 \mathrm{ml}$ water & $100 \mathrm{~g}$ \\
\hline Alanine & 8.4 \\
Arginine & 7.7 \\
Aspartic acid/asparagine & 4.5 \\
Glutamic acid/glutamine & 10.0 \\
Glycine & 23.3 \\
Histidine & 0.9 \\
Hydroxylysine & 1.5 \\
Hydroxyproline & 12.3 \\
Isoleucine & 1.2 \\
Leucine & 2.6 \\
Lysine & 3.3 \\
Methionine & 0.9 \\
Phenylalanine & 1.6 \\
Proline & 13.7 \\
Serine & 3.4 \\
Threonine & 1.9 \\
Tryptophan & 0.0 \\
Tyrosine & 0.6 \\
Valine & 2.2 \\
Carbohydrate (Glucodry 210) in 80 ml water & 50 \\
KCL & 0.094 \\
CaCl ${ }_{2}$ 2 $\mathrm{H}_{2} \mathrm{O}$ & 2.32 \\
L-tryptophan (TRP- group) & 0 \\
L-tryptophan (TRP + group) & 0.28 \\
\hline &
\end{tabular}

vortex-mixed vigorously and centrifuged at $50,000 \mathrm{~g}$ in a Hereaus Model Biofuge Stratos for $10 \mathrm{~min}$ at $4^{\circ} \mathrm{C}$. From the clear supernatant $20 \mu \mathrm{l}$ was mixed with $1,960 \mu \mathrm{l}$ water and $20 \mu \mathrm{l}$ norvaline and stored in the cooled $\left(7^{\circ} \mathrm{C}\right)$ sample compartment until analysis. In addition to total plasma TRP, the concentrations of several other amino acids were determined with a fully automated high-performance liquid chromatography (HPLC) system after precolumn derivatization with ophthaldialdehyde (OPA) (van Eijk et al. 1993). OPA-AA derivates were quantified with fluorescence detection. The concentrations of the total plasma TRP and other amino acids are expressed as $\mu \mathrm{mol} / \mathrm{l}$.

\section{Behaviour}

The object recognition test was performed to measure the effects of acute tryptophan depletion on cognition and was performed as described in detail elsewhere (Ennaceur and Delacour 1988; Prickaerts et al. 2002). The apparatus consisted of a circular arena, $83 \mathrm{~cm}$ in diameter. Half of the 40-cm-high wall was made of grey polyvinyl chloride, the other half of transparent polyvinyl chloride. The light intensity (20 Lux) was equal in the different parts of the apparatus. We used four different sets of objects that could not be displaced by a rat. Each object was available in triplicate. The different objects were: (1) a cone consisted of a grey polyvinyl chloride base (maximal diameter $18 \mathrm{~cm}$ ) with collar on top made of brass (total height $16 \mathrm{~cm}$ ), (2) a standard 11 transparent glass bottle (diameter $10 \mathrm{~cm}$, height $22 \mathrm{~cm}$ ) filled with water, (3) a massive metal cube $(10 \times 5 \times 7.5 \mathrm{~cm})$ with two holes (diameter $1.9 \mathrm{~cm})$, and (4) a massive aluminium cube with a tapering top $(13 \times 8 \times 8 \mathrm{~cm})$.

In the week preceding testing, the animals were adapted to the procedure, i.e., they were allowed to explore the apparatus (without any objects) twice for $3 \mathrm{~min}$. In the following days, the rats were tested until a stable discrimination performance was shown. A testing session comprised two trials. The duration of each trial was $3 \mathrm{~min}$. Two objects were placed in a symmetrical position about $10 \mathrm{~cm}$ away from the grey wall. A rat was always placed in the apparatus facing the wall at the middle of the front (transparent) segment. During the first trial the apparatus contained two identical objects. After the first exploration period the rat was put back in its home cage. One hour later the rat was put back in the apparatus for the second trial, but now with dissimilar objects, a familiar one and a new one. The duration of exploring each object in trial 1 and trial 2 was recorded manually with a personal computer. Exploration was defined as directing the nose to the object at a distance of no more than $2 \mathrm{~cm}$ and/or touching the object with the nose. Sitting on the object was not considered as exploratory behaviour. In order to avoid the 
Table 2 Overview of the effects of different treatment- and test conditions on the absolute TRP values in the different experiments

\begin{tabular}{|c|c|c|c|c|c|c|c|c|}
\hline \multirow[t]{2}{*}{ Exp } & \multicolumn{4}{|c|}{ Treatment groups } & \multicolumn{4}{|c|}{ Time (min): total plasma tryptophan levels $(\mu \mathrm{mol} / \mathrm{l})$} \\
\hline & $n$ & Sex & Treatment & Time effect & T0 & $\mathrm{T} 2$ & $\mathrm{~T} 4$ & T6 \\
\hline \multirow[t]{4}{*}{1} & 6 & M & $\mathrm{TRP}+$ & NS & $112.69(3.87)$ & $118.75(4.43)$ & $120.97(2.74)$ & $113.28(3.46)$ \\
\hline & 6 & M & 1TRP- & $P<0.001$ & $118.03(5.24)$ & $67.88^{+++, \times \times \times}(6.75)$ & $88.30^{+++, \times \times \times}(7.60)$ & $111.08(6.44)$ \\
\hline & 6 & M & 3TRP- & $P<0.001$ & $125.91(3.17)$ & $52.75^{+++, \times \times \times}(7.85)$ & $49.03^{+++, \times \times \times}(15.39)$ & $69.51^{+++, \times \times \times}(11.95)$ \\
\hline & 6 & M & Saline & NS & $133.50(4.77)$ & $127.35(6.28)$ & $135.39(6.34)$ & $118.41(4.43)$ \\
\hline \multirow[t]{3}{*}{2} & 4 & $\mathrm{~F}$ & $\mathrm{TRP}+$ & $P<0.05$ & $110.04(4.78)$ & $113.44(5.83)$ & $88.43(3.51)$ & $128.58(9.61)$ \\
\hline & 8 & $\mathrm{~F}$ & $\mathrm{TRP}++$ & $P<0.001$ & 112.38 & $32.90^{+++}$ & $54.59^{+++}$ & $100.05^{+}$ \\
\hline & 4 & $\mathrm{~F}$ & TRP- & $P<0.001$ & $105.16(7.18)$ & $217.28^{+++}(12.10)$ & $135.34^{+++}(6.28)$ & $104.91(8.33)$ \\
\hline \multirow[t]{2}{*}{3} & 3 & $\mathrm{~F}$ & $\mathrm{TRP}+$ & NS & $117.35(12.31)$ & $106.21(4.40)$ & $100.11(8.74)$ & \\
\hline & 7 & $\mathrm{~F}$ & TRP- & $P<0.001$ & $107.54(3.95)$ & $34.40^{+++}(2.55)$ & $38.54^{+++}(2.90)$ & \\
\hline
\end{tabular}

Mean (SEM); Exp experiment, $M$ male, $F$ female, $n$ number of animals per treatment group, $N S$ not significant

Treatment effect: difference from TRP+: ${ }^{+} P<0.05 ;{ }^{+++} P<0.001$; difference from saline: ${ }^{\times \times \times} P<0.001$

presence of olfactory trails, the objects were always thoroughly cleaned. Moreover, each object was available in triplicate so that none of the two objects from the first trial had to be used as the familiar object in the second trial. In addition, all combinations and locations of objects were used in a balanced manner to reduce potential biases due to preferences for particular locations or objects. After the rats were familiarised to the procedures of the task and had stable baseline $\mathrm{d} 2$ values, testing with treatment began.

\section{Results}

\section{Biochemistry}

The mean concentrations of plasma amino acids were determined for each treatment and time condition separately. The extent of reduction (expressed in absolute values and in percentage decline from resting values) was calculated for total plasma TRP concentrations and for the TRP/ $\Sigma$ LNAA ratio in experiments 1,2 , and 3. Extreme values were excluded from statistical analysis. Differences in plasma amino acid concentrations were analysed with Generalised Linear Models (GLM), with main factor 'treatment' and repeated measure factor 'time'. When appropriate, post hoc Bonferroni analyses were performed to further characterise the effects of treatment. Differences were regarded as statistically significant if $P<0.05$. An overview of the treatment effects on plasma TRP values of all experiments is shown in Table 2.

\section{Behaviour}

The basic measures in the object recognition test were the times spent by rats exploring an object during trial 1 and trial 2. The discrimination index $d 2$ [(exploration new object in trial 2-exploration familiar object in trial 2)/total exploration time during trial 2] was calculated for each treatment condition (see Rutten et al. 2007). $d 2$ is a relative index of discrimination between new and familiar object, because it corrects for total exploration time in trial 2 (see Şı et al. 2003). Effects of treatment, time, and interactions were analysed with univariate ANOVA.

Experiment 1: time and TRP- dose effects in males

This experiment consisted of four treatment conditions, with six male rats per group. The rats were treated either with one dose of TRP- (1TRP-), three doses of TRP- with 60-min intervals (3TRP-), one dose of TRP+ or one dose of saline. Blood samples were taken at baseline and again 2,4 , and $6 \mathrm{~h}$ after baseline blood samples.

\section{Plasma TRP}

There was a Time $\times$ Treatment interaction effect on TRP levels $\left[F_{(9,54)}=14.31, P<0.001\right]$. TRP levels changed over the $6 \mathrm{~h}$ [Time: $\left.F_{(3,54)}=27.07, P<0.001\right]$ and there was a treatment effect on TRP levels $\left[F_{(3,18)}=17.27\right.$, $P<0.001]$. Post hoc analysis showed that TRP levels were higher in the saline condition than in both TRPconditions. TRP levels in the TRP+ condition were higher than in the 3TRP-condition. There was no significant difference between the two TRP- conditions, and between the saline and TRP+ condition. Separate analyses for each treatment condition indicated that there was a significant time effect on TRP levels in both TRP-conditions [1TRP-: $F_{(3,15)}=21.65, P<0.001 ; 3$ TRP-: $F_{(3,9)}=22.11$, $P<0.001)$, but not in the TRP + and the saline condition (see Table 2). 


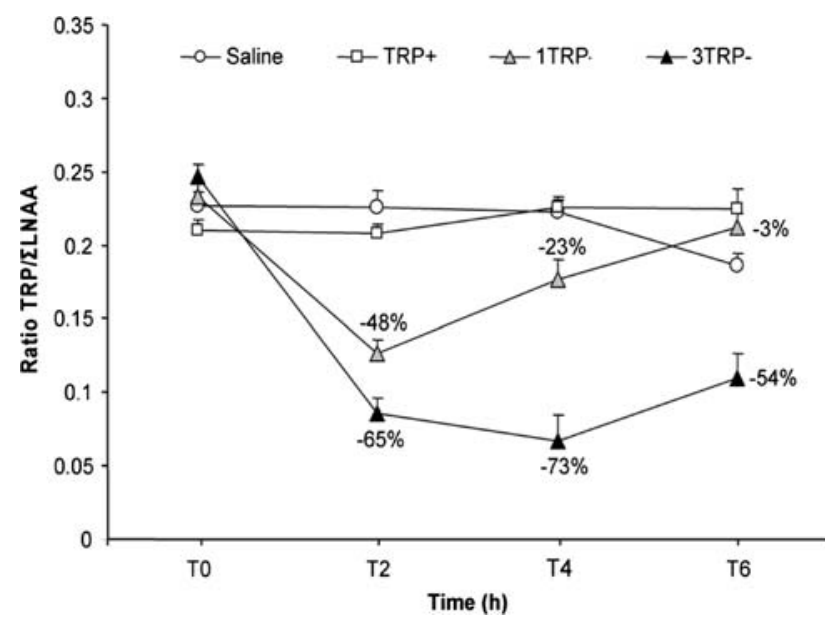

Fig. 1 Experiment 1: time and TRP- dose effects in males. The effects of treatment on the ratio plasma TRP/ $\Sigma$ LNAA (mean values and SEM). Percentages indicate the difference from baseline levels in the TRP- conditions

\section{Plasma TRP/LLNAA ratio}

There was a Time $\times$ Treatment interaction effect on the TRP/ $\Sigma$ LNAA ratio $\left[F_{(9,45)}=21.51, \quad P<0.001\right]$. The TRP/ $L$ LNAA ratio changed over the 6-h [Time: $\left.F_{(3,45)}=37.31, P<0.001\right]$. There was a treatment effect on the TRP/ $/$ LNAA ratio $\left[F_{(3,15)}=22.24, P<0.001\right]$, post hoc analysis revealed that the 3TRP- condition was different from all other treatment conditions. There were no significant differences between other treatment conditions. Separate analyses for each treatment condition showed that there was a significant time effect on the TRP/ $\Sigma$ LNAA ratio in both TRP- conditions and in the saline condition [1TRP-: $F_{(3,12)}=20.01, P<0.001$; 3TRP-: $F_{(3,9)}=54.74, P<0.001$; Saline: $F_{(3,12)}=6.12$, $P<0.01$ ], but not in the TRP+ condition. Treatment effects on the TRP/ $\Sigma$ LNAA ratio are shown in Fig. 1.

Experiment 2: time and dose effects of acute TRP depletion and suppletion in females

In this experiment, female rats were treated with TRP- on 1 day and with TRP+ or TRP++ on another day. They received two doses with 90 min interval. The TRP++ mixture contained $2.8 \%$ TRP, which is ten times the amount of TRP that is used for the normal balanced TRP+ mixture. Thus, the TRP ++ condition results in TRP suppletion. Blood samples were taken at baseline and 2, 4, and $6 \mathrm{~h}$ after the first injection.

\section{Plasma TRP}

There was a Time $\times$ Treatment interaction effect on TRP levels $\left[F_{(6,27)}=37.21, P<0.001\right]$. There was an effect

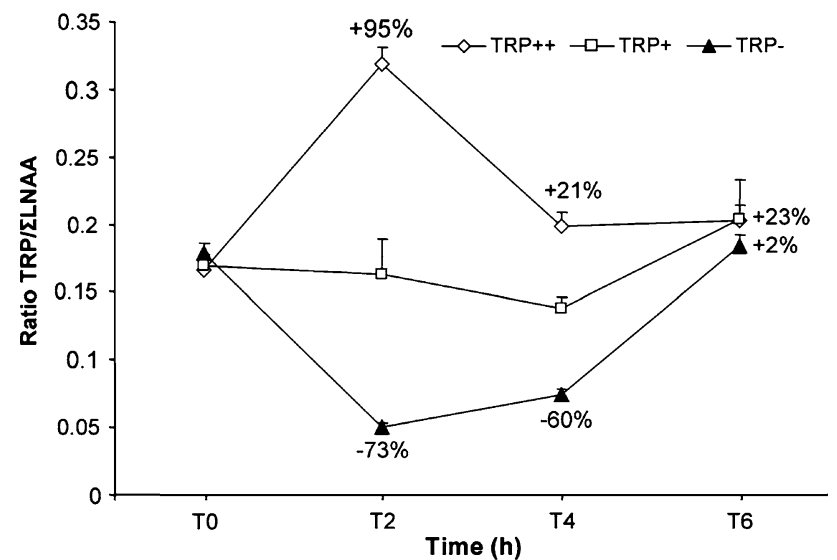

Fig. 2 Experiment 2: time and dose effects of acute TRP depletion and suppletion in females. The effects of treatment on the ratio plasma TRP/ $\Sigma$ LNAA (mean values and SEM). Percentages indicate the difference from baseline levels in the TRP depletion and TRP suppletion condition

of time $\left[F_{(3,27)}=8.61, \quad P<0.001\right]$ and treatment $\left[F_{(2,9)}=126.02, P<0.001\right]$ on TRP levels. Post hoc analysis revealed that the TRP levels in all treatment groups were significantly different (see Table 2). Separate analyses for each treatment condition revealed that there was a time effect on TRP levels in all treatment conditions [TRP-: $F_{(3,9)}=84.80, P<0.001 ;$ TRP $+: F_{(3,9)}=6.60$, $P<0.05 ;$ TRP $\left.++: F_{(3,9)}=27.94\right]$.

\section{Plasma TRP/LLNAA ratio}

There was a Time $\times$ Treatment interaction effect on the TRP $/ \Sigma$ LNAA ratio $\left[F_{(6,24)}=30.75, P<0.001\right]$. There was a time effect $\left[F_{(3,24)}=15.37, P<0.001\right]$ and a treatment effect $\left[F_{(2,8)}=15,77, P<0.01\right]$ on the TRP/ $\Sigma$ LNAA ratio. Post hoc analysis showed that the TRP/ $\Sigma$ LNAA ratio in the TRP ++ condition was significantly different from that in the TRP- and TRP+ condition, while TRP- and TRP+ did not differ significantly. Separate analyses for each treatment condition revealed that there was an effect of time on the TRP/ $/$ LNAA ratio in all treatment conditions [TRP-: $F_{(3,6)}=52.29, P<0.001$; TRP+: $F_{(3,9)}=4.48, P<0.05$; TRP $++: F_{(3,9)}=40.43$, $P<0.001]$. Treatment effects on the TRP/ $\Sigma$ LNAA ratio are shown in Fig. 2.

Experiment 3: effects of repeated treatment

Female rats were treated on four consecutive days with TRP- first and 1 week later on four consecutive days with TRP+. The rats were daily injected with two doses with $90 \mathrm{~min}$ interval. They had access to normal food in the afternoon of each day. In the evening, food was taken away again ( $14 \mathrm{~h}$ before treatment the next day). On the 


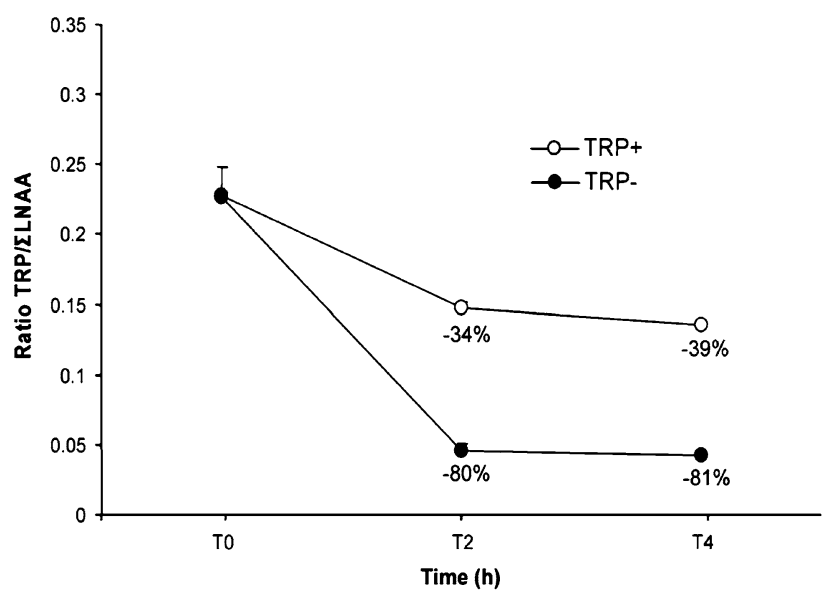

Fig. 3 Experiment 3: effects of repeated treatment. Effects of treatment on the ratio plasma TRP/ $\Sigma$ LNAA (mean values and SEM). Percentages indicate difference from baseline levels

fourth day, blood samples were taken at baseline, and 2 and $4 \mathrm{~h}$ after the first injection.

After four consecutive days of administration of TRP- or $\mathrm{TRP}+$, with blood samples being taken on the fourth day, Time $\times$ Treatment interaction effects were found on TRP $\left[F_{(2,14)}=35.54, P<0.001\right]$ and the TRP/ $\Sigma$ LNAA ratio $\left[F_{(2,12)}=23.78, P<0.001\right]$. There was an effect of time on TRP $\left[F_{(2,14)}=77.39, P<0.001\right]$ and on the TRP/ $\Sigma$ LNAA ratio $\left[F_{(2,12)}=189.34, P<0.001\right]$. The time effect on the TRP/ $\Sigma$ LNAA was significant for both treatment condition $\left[\mathrm{TRP}+: F_{(2,4)}=14.68, P<0.05\right.$; TRP-: $\left.F_{(2,8)}=565.03, P<0.001\right]$, but there was a time effect on TRP only in the TRP- condition $\left[F_{(2,10)}=222.55\right.$, $P<0.001]$. There were treatment effects on TRP $\left[F_{(1,7)}=61.49, P<0.001\right]$ and the TRP/ $/$ LNAA ratio $\left[F_{(1,6)}=99.13, P<0.001\right]$. Treatment effects on the TRP/ $\Sigma$ LNAA ratio are shown in Fig. 3, effects on TRP are shown in Table 2.

When comparing the TRP- after four consecutive treatment days with the TRP- condition of 1 day administration that was taken earlier in the same animals (experiment 2), an interaction effect was not found for TRP [Time $\times$ Treatment: $\left.F_{(2,16)}=2.66, \mathrm{NS}\right]$, but this interaction was significant for the TRP $/ \Sigma$ LNAA ratio $\left[F_{(2,12)}=14.80, P<0.001\right]$. There was a time effect for TRP $\left[F_{(2,16)}=279.22\right.$, $P<0.001]$ and the TRP $/ \Sigma$ LNAA ratio $\left[F_{(2,12)}=304.23\right.$, $P<0.001]$. Treatment effects were not found, neither for TRP $\left[F_{(1,8)}=0.29, \mathrm{NS}\right]$ nor for the TRP/ $\Sigma$ LNAA ratio $\left[F_{(1,6)}=0.78, \mathrm{NS}\right]$.

When comparing the TRP+ after four consecutive treatment days with the TRP + condition of 1 day administration that was taken earlier in the same animals (experiment 2), an interaction effect was not found for TRP [Time $\times$ Treatment: $F_{(2,8)}=3.52, N S$ ], but this interaction was marginally significant for the TRP/ $\Sigma$ LNAA ratio

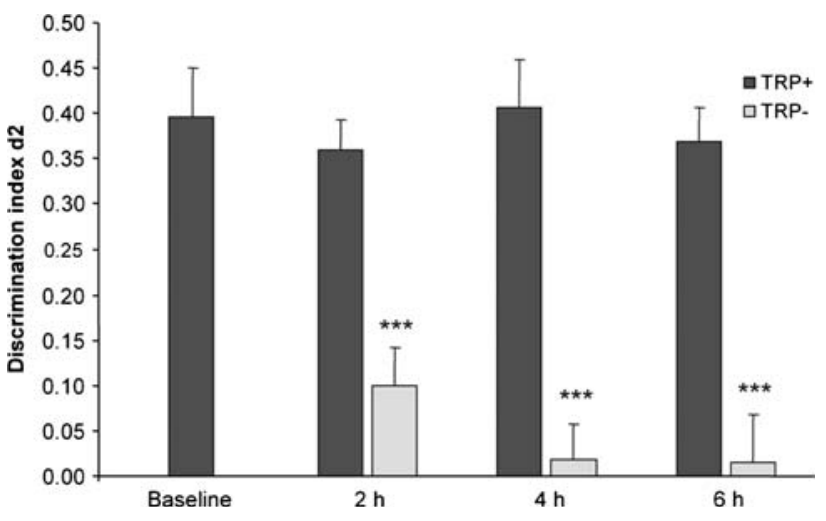

Fig. 4 Experiment 4: effects of ATD on object recognition memory. Effects of treatment on discrimination index $d 2$ (mean values and SEM). Statistical significance $* * * P<0.001$ compared to TRP+

$\left[F_{(2,8)}=4.23, P=0.056\right]$. There was a time effect for TRP $\left[F_{(2,8)}=10.18, P<0.05\right]$ and the TRP/ $\Sigma$ LNAA ratio $\left[F_{(2,8)}=10.78, P<0.05\right]$. Treatment effects were not found, neither for TRP $\left[F_{(1,4)}=0.1, \mathrm{NS}\right]$ nor for the TRP/ $\Sigma$ LNAA ratio $\left[F_{(1,4)}=0.23, \mathrm{NS}\right]$.

Experiment 4: effects of ATD on object recognition memory

Male rats $(n=24)$ were repeatedly treated with TRP- and TRP + on different days. They received two doses with $90 \mathrm{~min}$ interval and were repeatedly tested in the object recognition test. There was a 1-h interval between the two trials of the test, trial 1 took place at 2, 4, or $6 \mathrm{~h}$ after the first treatment on different testing days. There was a treatment effect on discrimination index $d 2 \quad\left[F_{(1,137)}=88.73\right.$, $P<0.001$ ], TRP- treated rats had a lower $d 2$ than TRP+ treated rats (Fig. 4). There was no effect of Time or a Time $\times$ Treatment interaction effect on $d 2$. The treatment effect was significant at all time points [ $2 \mathrm{~h}: F_{(1,45)}=23.42$, $P<0.001 ; 4 \mathrm{~h}: F_{(1,45)}=35.14, P<0.001 ; 6 \mathrm{~h}: F_{(1,45)}=$ $30.42, P<0.001]$.

\section{Discussion}

Acute tryptophan depletion resulted in a transient lowering of plasma TRP and the TRP/ $\Sigma$ LNAA ratio in males and females. To the best of our knowledge, this is the first study to give a detailed description of the effects of different doses of acute tryptophan depletion and suppletion in adult male and female Wistar rats. The exact characteristics of the depletion seemed to depend on the number of doses, or the amount of the TRP- mixture, the rat received. It appeared that the number of dosages the male rats received in experiment 1 influenced both the duration of the depletion and its intensity. After one dose of TRP- the TRP/ $\Sigma$ LNAA 
ratio was not significantly different from that in the TRP+ and saline condition. Thus, one dose may not be sufficient to cause significant depletion of the TRP/ $\mathrm{L}$ NAA ratio. As the level of plasma TRP $/ \Sigma$ LNAA depletion is about $70 \%$ with two and three doses, this level may represent the highest level of depletion that can be achieved using the method of acute tryptophan depletion. Three doses of TRP- did not result in lower TRP levels, but in longer duration of the TRP depletion, which is of course at least partly explained by the fact that the rats received their TRP- injections staggered over a longer period of time.

Two doses of ATD resulted in depletion of TRP and the TRP/ $\Sigma$ LNAA ratio in both males and females. When the effects of two doses TRP- are compared to a study in which males were treated with two doses TRP- (Lieben et al. 2004b), females showed similar levels of depletion at $2 \mathrm{~h}$, but less depletion than males at 4 and $6 \mathrm{~h}$. Although one should be cautious when comparing different studies, a recent study comparing ATD effects in males and females directly also showed slightly stronger depletion in males $4 \mathrm{~h}$ after treatment with two doses (Jans et al. 2007a). It is striking that at $6 \mathrm{~h}$, the female TRP/ $\Sigma$ LNAA ratio was back at baseline levels (experiment 2), while the male ratio still showed a treatment effect, with $49 \%$ depletion (Lieben et al. 2004b). TRP levels showed the same effect, with $11 \%$ depletion they were almost back to baseline levels in females at $6 \mathrm{~h}$ (experiment 2), but in males they were still $30 \%$ lower than baseline levels (Lieben et al. 2004b). It might be possible that females have a faster metabolism and reach peak depletion faster than males and also return to baseline levels faster. It is also interesting to note that in females the TRP/ $\Sigma$ LNAA ratio returned to baseline levels faster than plasma TRP levels, whereas the opposite occurred in males. In males, plasma TRP depletion was less than depletion of the TRP/ $\Sigma$ LNAA ratio at $6 \mathrm{~h}$ after the first dose (Lieben et al. 2004b).

ATD resulted in significant impairment of object recognition measured 2, 4, or $6 \mathrm{~h}$ after the first of two ATD doses. Previously, reliable memory effects have been found $4 \mathrm{~h}$ after the first treatment with two doses in males (Lieben et al. 2004b) and females (Jans et al. 2007a), despite stronger depletion effects on TRP/ $\Sigma$ LNAA in males. Experiment 4 of this study showed that already at $2 \mathrm{~h}$ there is a significant impairment of object recognition memory, suggesting central depletion effects at this time point. This experiment also showed that object recognition memory in males is still impaired $6 \mathrm{~h}$ after ATD treatment, in spite of decreasing treatment effects on plasma TRP levels at that time point. It can be concluded that two doses of ATD impaired object recognition memory and that this effect is both rapid and long lasting.

From experiment 1 it may be concluded that TRP+ treatment is an appropriate control condition, because the
TRP/ $L$ LNAA ratio was stable over time in the TRP+ condition. The TRP+ condition has nutritional value whereas saline does not. Therefore, in a saline condition amino acid levels may drop over time as a result of lack of food intake, as the animals are deprived of normal food for $14 \mathrm{~h}$ before treatment and during the treatment period. In experiment 1 plasma TRP levels were stable over time in both the TRP + and the saline condition, suggesting treatment may affect the other LNAAs. In females, experiment 2 of this study, a time effect was found in the TRP+ condition, plasma TRP and the TRP/ 2 LNAA ratio dropped a bit over $6 \mathrm{~h}$, both were especially low at $4 \mathrm{~h}$. These effects, however, were not replicated in a later experiment (Jans et al. 2007a), where TRP levels were stable over time in the TRP + condition in males and both groups of females. The TRP/ $\Sigma$ LNAA ratio did decrease over time (Jans et al. 2007a) again suggesting treatment effects on other LNAAs.

It is important to note that the TRP+ control condition of this protein-carbohydrate mixture does not result in an increase in TRP levels, whereas this increase has been reported in TRP+ rats when using an amino acid mixture that is often used in human ATD studies (Blokland et al. 2004). Suppletion of TRP, as in the TRP ++ condition in experiment 2, caused a fast increase of both TRP levels and the TRP/ $\Sigma$ LNAA ratio that is most pronounced $2 \mathrm{~h}$ after the first injection. Six hours after the first injection, TRP levels are back to baseline levels, while the TRP/ $\Sigma$ LNAA ratio is at that time point still somewhat higher than baseline levels.

It could be argued that repeated treatment with the TRPdiet might affect the level of depletion (e.g. adaptation to diet). However, we observed that repeated exposure to ATD does not affect the depletion effects. When comparing TRPtreatment on 1 day with treatment on four consecutive days, there was no significant difference in TRP levels or TRP/ $\Sigma$ LNAA ratio. In the TRP + condition the TRP/ $\Sigma$ LNAA ratio decreased over time on the fourth day of treatment, but there was no difference when comparing 1 day of TRP+ treatment with treatment on four consecutive days. The effects of ATD are transient, TRP levels return to baseline several hours after treatment on the day that the rat is treated, even when the rats do not have access to food. When the rats were treated on four consecutive days, baseline levels and treatment effects on the fourth day were similar to the effects of 1-day treatment. This may be an important finding, as in rat ATD studies a protocol with treatment on several consecutive days is not uncommon (Blokland et al. 2002; Lieben et al. 2004b; Jans et al. 2007a).

It should be noted that in experiment 1 of the present study and a previous study (Lieben et al. 2004b) the protein Solugel $\mathrm{C}$ was used, whereas in experiments 2,3 , and 4 of the present study and several other studies (Lieben et al. 2004a; Jans 
et al. 2007a) Solugel $P$ was used in the protein-carbohydrate mixture. The difference between these two products is that they differ in sensory characteristics (i.e., smell and taste). However, as there are no differences in composition, molecular weight and length of the collagen hydrolysate chains between Solugel P and C, this is unlikely to explain differences in treatment effects in these experiments.

In conclusion, the method of ATD can be used to temporarily lower peripheral tryptophan levels and consequently affect 5-HT levels. A protocol with two injections with 90 min interval or one with three injections with $60 \mathrm{~min}$ interval resulted in depletion of peripheral TRP levels of about $65-70 \% 2-4 \mathrm{~h}$ after the first treatment. Object recognition was impaired 2, 4, and $6 \mathrm{~h}$ after the first of two doses ATD, suggesting that the central effects of ATD occurred rapidly and continued until at least $6 \mathrm{~h}$ after the first of two doses, in spite of decreasing treatment effects on plasma TRP levels at that time point. The number of doses the rat receives appears to mainly affect the duration of the depletion as the doses are staggered over a longer period of time. Two doses of TRP- appeared to result in comparable depletion of TRP and TRP/ $\Sigma$ LNAA in males and females, although females may return to baseline levels faster than males. Treatment effects after 1 day of treatment were not different from treatment effects after four consecutive days of treatment. $\mathrm{TRP}+$ treatment appeared to be an appropriate control condition. This method of ATD can provide a useful tool to study the effects of a transient lowering of 5-HT levels on cognition and symptoms of depression and anxiety in both humans and rats. ATD results in impaired memory, but affects mood only in subjects that are vulnerable to develop depression (Riedel et al. 1999; Riedel et al. 2002; Booij and Van der Does 2007). By challenging the 5-HT system, ATD can be used to assess the vulnerability of that system and the role it plays in normal and pathological behaviour (Jans et al. 2007b).

Open Access This article is distributed under the terms of the Creative Commons Attribution Noncommercial License which permits any noncommercial use, distribution, and reproduction in any medium, provided the original author(s) and source are credited.

\section{References}

Bel N, Artigas F (1996) Reduction of serotonergic function in rat brain by tryptophan depletion: effects in control and fluvoxamine-treated rats. J Neurochem 67:669-676

Biggio G, Fadda F, Fanni P, Tagliamonte A, Gessa GL (1974) Rapid depletion of serum tryptophan, brain tryptophan, serotonin and 5-hydroxyindoleacetic acid by a tryptophan-free diet. Life Sci 14:1321-1329

Blokland A, Lieben C, Deutz NE (2002) Anxiogenic and depressivelike effects, but no cognitive deficits, after repeated moderate tryptophan depletion in the rat. J Psychopharmacol 16:39-49
Blokland A, Lieben C, Deutz NEP, Schmitt J (2004) Acute tryptophan depletion: comparing the effects of an amino acid mixture with a gelatin-based protein in man and rat. Curr Top Nutraceut Res 2:161-169

Booij L, Van der Does AJ (2007) Cognitive and serotonergic vulnerability to depression: convergent findings. J Abnorm Psychol 116:86-94

Booij L, Van der Does W, Benkelfat C, Bremner JD, Cowen PJ, Fava M, Gillin C, Leyton M, Moore P, Smith KA, Van der Kloot WA (2002) Predictors of mood response to acute tryptophan depletion. A reanalysis. Neuropsychopharmacology 27:852-861

Booij L, Van der Does AJ, Riedel WJ (2003) Monoamine depletion in psychiatric and healthy populations: review. Mol Psychiatry 8:951-973

Carpenter LL, Anderson GM, Pelton GH, Gudin JA, Kirwin PD, Price LH, Heninger GR, McDougle CJ (1998) Tryptophan depletion during continuous CSF sampling in healthy human subjects. Neuropsychopharmacology 19:26-35

Ellenbogen MA, Young SN, Dean P, Palmour RM, Benkelfat C (1996) Mood response to acute tryptophan depletion in healthy volunteers: sex differences and temporal stability. Neuropsychopharmacology 15:465-474

Ennaceur A, Delacour J (1988) A new one-trial test for neurobiological studies of memory in rats. 1: Behavioral data. Behav Brain Res 31:47-59

Fernstrom JD (1981) Dietary precursors and brain neurotransmitter formation. Annu Rev Med 32:413-425

Fluttert M, Dalm S, Oitzl MS (2000) A refined method for sequential blood sampling by tail incision in rats. Lab Anim 34:372-378

Jans LA, Lieben CK, Blokland A (2007a) Influence of sex and estrous cycle on the effects of acute tryptophan depletion induced by a gelatin-based mixture in adult Wistar rats. Neuroscience 147:304-317

Jans LA, Riedel WJ, Markus CR, Blokland A (2007b) Serotonergic vulnerability and depression: assumptions, experimental evidence and implications. Mol Psychiatry 12:522-543

Lieben CK, Blokland A, Westerink B, Deutz NE (2004a) Acute tryptophan and serotonin depletion using an optimized tryptophan-free protein-carbohydrate mixture in the adult rat. Neurochem Int 44:9-16

Lieben CK, van Oorsouw K, Deutz NE, Blokland A (2004b) Acute tryptophan depletion induced by a gelatin-based mixture impairs object memory but not affective behavior and spatial learning in the rat. Behav Brain Res 151:53-64

Maes M, Meltzer HY (1995) The serotonin hypothesis of major depression. In: Bloom FE, Kupfer DJ (eds) Psychopharmacology: the fourth generation of progress. Raven Press Ltd, New York, pp 933-944

Moja EA, Cipolla P, Castoldi D, Tofanetti O (1989) Dose-response decrease in plasma tryptophan and in brain tryptophan and serotonin after tryptophan-free amino acid mixtures in rats. Life Sci 44:971-976

Moja EA, Restani P, Corsini E, Stacchezzini MC, Assereto R, Galli CL (1991) Cycloheximide blocks the fall of plasma and tissue tryptophan levels after tryptophan-free amino acid mixtures. Life Sci 49:1121-1128

Moore P, Landolt HP, Seifritz E, Clark C, Bhatti T, Kelsoe J, Rapaport M, Gillin JC (2000) Clinical and physiological consequences of rapid tryptophan depletion. Neuropsychopharmacology 23:601-622

Nishizawa S, Benkelfat C, Young SN, Leyton M, Mzengeza S, de Montigny C, Blier P, Diksic M (1997) Differences between males and females in rates of serotonin synthesis in human brain. Proc Natl Acad Sci USA 94:5308-5313

Park SB, Coull JT, McShane RH, Young AH, Sahakian BJ, Robbins TW, Cowen PJ (1994) Tryptophan depletion in normal 
volunteers produces selective impairments in learning and memory. Neuropharmacology 33:575-588

Prickaerts J, van Staveren WC, Şık A, Markerink-van Ittersum M, Niewohner U, van der Staay FJ, Blokland A, de Vente J (2002) Effects of two selective phosphodiesterase type 5 inhibitors, sildenafil and vardenafil, on object recognition memory and hippocampal cyclic GMP levels in the rat. Neuroscience 113:351-361

Reilly JG, McTavish SF, Young AH (1997) Rapid depletion of plasma tryptophan: a review of studies and experimental methodology. J Psychopharmacol 11:381-392

Riedel WJ, Klaassen T, Deutz NE, van Someren A, van Praag HM (1999) Tryptophan depletion in normal volunteers produces selective impairment in memory consolidation. Psychopharmacology (Berl) 141:362-369

Riedel WJ, Klaassen T, Schmitt JA (2002) Tryptophan, mood, and cognitive function. Brain Behav Immun 16:581-589

Rutten K, Lieben C, Smits L, Blokland A (2007) The PDE4 inhibitor rolipram reverses object memory impairment induced by acute tryptophan depletion in the rat. Psychopharmacology (Berl) 192:275-282

Sambeth A, Blokland A, Harmer CJ, Kilkens TO, Nathan PJ, Porter RJ, Schmitt JA, Scholtissen B, Sobczak S, Young AH, Riedel WJ (2007) Sex differences in the effect of acute tryptophan depletion on declarative episodic memory: a pooled analysis of nine studies. Neurosci Biobehav Rev 31:516-529

Şık A, van Nieuwehuyzen P, Prickaerts J, Blokland A (2003) Performance of different mouse strains in an object recognition task. Behav Brain Res 147:49-54

Smith KA, Fairburn CG, Cowen PJ (1997) Relapse of depression after rapid depletion of tryptophan. Lancet 349:915-919

Stancampiano R, Melis F, Sarais L, Cocco S, Cugusi C, Fadda F (1997) Acute administration of a tryptophan-free amino acid mixture decreases 5-HT release in rat hippocampus in vivo. Am J Physiol 272:R991-R994

van Eijk HM, Rooyakkers DR, Deutz NE (1993) Rapid routine determination of amino acids in plasma by high-performance liquid chromatography with a $2-3$ microns Spherisorb ODS II column. J Chromatogr 620:143-148

Williams WA, Shoaf SE, Hommer D, Rawlings R, Linnoila M (1999) Effects of acute tryptophan depletion on plasma and cerebrospinal fluid tryptophan and 5-hydroxyindoleacetic acid in normal volunteers. J Neurochem 72:1641-1647

Wurtman RJ, Hefti F, Melamed E (1980) Precursor control of neurotransmitter synthesis. Pharmacol Rev 32:315-335

Young SN, Smith SE, Pihl RO, Ervin FR (1985) Tryptophan depletion causes a rapid lowering of mood in normal males. Psychopharmacology (Berl) 87:173-177 